\title{
Effects of the supine and prone position on diaphragm thickness in healthy term infants
}

\author{
Virender K Rehan, James M Nakashima, Aliza Gutman, Lewis P Rubin, F Dennis McCool
}

Department of

Pediatrics, Memorial

Hospital of Rhode

Island, Pawtucket,

Rhode Island, USA

V K Rehan

A Gutman

Department of Pathology, Memorial Hospital of Rhode

Island

J M Nakashima

Department of Medicine, Memorial Hospital of Rhode

Island

F D McCool

Department of Pediatrics, Women and Infants Hospital, Brown University School of Medicine,

Providence, Rhode

Island

L P Rubin

Correspondence to: Dr V K Rehan, Harbor UCLA Medical Center, Research and Education Institute-RB1, 1124 West Carson Street, Torrance, CA 90502, USA

email: vrehan@prl.humc.edu

Accepted 30 March 2000

\begin{abstract}
Background-The physiological basis underlying the decline in the incidence of sudden infant death syndrome (SIDS) associated with changing the sleep position from prone to supine remains unknown.

Aims-To evaluate diaphragm thickness $\left(t_{\mathrm{di}}\right)$ and shortening in healthy term infants in the prone and supine positions in order to determine whether changes in body position would affect diaphragm resting length and the degree of diaphragm shortening during inspiration.

Methods-In 16 healthy term infants, diaphragm thickness at the level of the zone of apposition on the right side was measured using ultrasonography. Heart rate (HR), breathing frequency (f), and transcutaneous oxyhaemoglobin saturation $\left(\mathrm{SaO}_{2}\right)$ were recorded simultaneously during diaphragm imaging with the infants in the supine and prone positions during quiet sleep.

Results-At end expiratory (EEV) and at end inspiratory lung volumes (EIV), $t_{\mathrm{di}}$ increased significantly in the prone position. The change in $t_{\mathrm{di}}$ during tidal breathing was also greater when the infant was prone. $\mathrm{SaO}_{2}, \mathrm{HR}$, and $\mathrm{f}$ were not significantly different at EEV and at EIV in both positions.

Conclusion-In healthy term infants, placed in the prone position, the diaphragm is significantly thicker and, therefore, shorter, both at EEV and EIV. Diaphragm shortening during tidal breathing is greater when the infant is prone. In the prone position, the decreased diaphragm resting length would impair diaphragm strength, and the additional diaphragm shortening during tidal breathing represents added work performed by the diaphragm. This may compromise an infant's capacity to respond to stressful situations when placed in the prone position and may contribute to the association of SIDS with prone position. (Arch Dis Child 2000;83:234-238)
\end{abstract}

Keywords: diaphragm; infant; sudden infant death syndrome; sleep position

There is a strong association between the prone sleep position and sudden infant death syndrome (SIDS)..$^{1-9}$ Proposed, but uncertain, mechanisms underlying this association include upper airway obstruction, rebreathing of expired air, thermal stress, reduced cerebral blood flow, and a higher arousal threshold. ${ }^{10-17}$ However, no adverse effects of the prone position on respiratory mechanics have been found in term infants, and, to the contrary, studies of preterm infants suggest that the prone position is physiologically advantageous. ${ }^{18-24}$ Consequently, no specific posture induced compromise of respiratory mechanics has been linked with SIDS. Differences in diaphragm function between the prone and supine positions, however, have not been fully explored in infants.

The diaphragm is the primary respiratory muscle for the neonate and performs the majority of the work of breathing. ${ }^{25}$ In the prone position, alterations in respiratory system mechanics or changes in lung volume may affect the resting length of the diaphragm or the degree to which it shortens during inspiration. The effect of the prone position on diaphragm length, however, has not been studied in infants. We postulate that position induced alteration in diaphragm function may explain, in part, the association of the prone sleep position with SIDS. The purpose of this study was to evaluate position related alterations in diaphragm resting length and diaphragm shortening during tidal breathing in healthy term infants. Our premise was that diaphragm length and, therefore, diaphragm function, differs in the prone and supine sleep positions.

\section{Methods}

After written parental consent, 16 healthy term (eight boys and eight girls) appropriate for gestational age infants who had no clinical evidence of cardiorespiratory compromise or any other illness were studied within two days of delivery, except for one infant who was studied on day 17 of life (table 1). Birth and study weights were $3.3(0.6) \mathrm{kg}$ (mean (SD)) and mean head circumference and body length were 33.5 (2) $\mathrm{cm}$ and 50 (3) $\mathrm{cm}$, respectively. Mean gestational age was 39 (0.9) weeks, and postnatal age was 3 (4) days. Twelve infants were delivered vaginally and four by Caesarean section. Their mean Apgar scores were 9 (1) and $9(0)$ at one and five minutes, respectively.

All infants were studied in a nursery while sleeping comfortably under a radiant warmer. Studies were performed about one hour postprandially during quiet sleep. If the infant became agitated, he or she was calmed with a pacifier. All studies were completed within 30 minutes. The infants were randomly assigned to either the supine or prone position. After obtaining data in the initial position, the infants were repositioned and allowed to settle down in the other position before being restudied. In 
Table 1 Patient characteristics

\begin{tabular}{ll}
\hline Healthy term infants (no.) & 16 \\
Gender & $8 \mathrm{M}, 8 \mathrm{~F}$ \\
Birth weight (kg) & $3.3(0.6)$ \\
Study weights (kg) & $3.3(0.6)$ \\
Gestational age (wk) & $39(0.9)$ \\
Postnatal age (days) & $3(4)$ \\
Mode of delivery & $12 \mathrm{~V}, 4 \mathrm{CS}$ \\
Head circumference (cm) & $33.5(2)$ \\
Body length (cm) & $50(3)$ \\
Apgar scores & \\
$\quad(1$ min) & $9(1)$ \\
$\quad(5$ min) & $9(0)$ \\
\hline
\end{tabular}

Results expressed as mean (SD).

$\mathrm{V}$, vaginal; CS, Caesarean section.

both positions, the head was placed sideways. When prone, the infant's abdominal wall was resting against the mattress.

Infant sleep states were characterised as active or quiet according to behavioural criteria. ${ }^{26}$ Active sleep was defined by rapid eye movements, frequent body and facial movements, and irregular breathing with paradoxical movements of the rib cage and abdomen. Quiet sleep was defined as no eye movements, rare body or facial movements with occasional startles, and regular breathing with synchronised movements of the rib cage and abdomen.

A $7.5 \mathrm{MHz}$ ultrasound transducer was used to obtain two dimensional images of the diaphragm at the level of the zone of apposition of the right hemithorax. The diaphragm was visualised in the right mid-axillary line at the level of the eighth or ninth intercostal space. Using the B mode, two dimensional coronal images of the diaphragm were generated and selected for clarity and parallelism of the three reflective layers of diaphragm structure (the muscle, pleural, and peritoneal membranes). At least five respiratory cycles were recorded and then replayed. We used the freeze frame control during the replay to precisely determine the end inspiration and end expiration. Diaphragm thickness $\left(t_{\mathrm{di}}\right)$ was measured as the distance between the midpoints of the peritoneal and pleural layers at end inspiratory volume (EIV) and end expiratory volume (EEV). The diaphragm thickness was measured to the nearest $0.1 \mathrm{~mm}$, which is within the range of the accuracy of the transducer. All scans were performed by a single investigator (FDM). When repeated measurements were obtained for each infant at a given lung volume, the coefficients of variation for $t_{d i}$ were less than $10 \%$. The reproducibility of $t_{d i}$ can be in part be attributed to studying the infants during quiet sleep where the breathing pattern is regular and the ultrasound images can be reviewed and recorded. Heart rate $(\mathrm{HR})$, respiratory rate $(\mathrm{f})$, and oxyhaemoglobin saturation $\left(\mathrm{SaO}_{2}\right)$ were measured continuously by a cardiorespiratory monitor (Datascope) and were recorded simultaneously during diaphragm imaging.

Diaphragm thickness and all physiological variables were recorded at end EEV and EIV in both positions. The change in $t_{d i}\left(\Delta t_{d i}\right)$ during inspiration was calculated as the difference between $t_{\mathrm{di}}$ at EEV and at EIV. A paired $t$ test was used to determine the significance of differences in $\mathrm{t}_{\mathrm{di}}$ and $\Delta \mathrm{t}_{\mathrm{di}}$ between the two posi-
Table 2 Physiological parameters, $t_{d i}$, and $\Delta t_{d i}$ in supine and prone positions

\begin{tabular}{|c|c|c|c|}
\hline & Supine & Prone & $\begin{array}{l}\text { Prone-supine } \\
(95 \% \mathrm{CL})\end{array}$ \\
\hline $\mathrm{t}_{\mathrm{di}}$ at $\mathrm{EEV}(\mathrm{mm})$ & $1.97(0.3)$ & $2.24(0.4)^{\star}$ & $0.15-0.41$ \\
\hline $\mathrm{t}_{\mathrm{di}}$ at $\mathrm{EIV}(\mathrm{mm})$ & $2.36(0.3) \dagger$ & $2.91(0.4)^{\star} \dagger$ & $0.33-0.63$ \\
\hline$\Delta \mathrm{t}_{\mathrm{di}}(\mathrm{mm})$ & $0.39(0.04)$ & $0.64(0.1)^{\star}$ & $0.02-0.48$ \\
\hline \multicolumn{4}{|l|}{$\mathrm{SaO}_{2}(\%)$} \\
\hline At EEV & $98.8(1.6)$ & $99.1(1.2)$ & $0.37-1.88$ \\
\hline At EIV & $99.5(0.9)$ & $98.9(1.4)$ & $0.44-1.43$ \\
\hline \multicolumn{4}{|c|}{ Heart rate (beats per min) } \\
\hline At EEV & $127(12)$ & $128(14)$ & $5.7-15.5$ \\
\hline At EIV & $122(15)$ & $127(13)$ & $4.1-14.9$ \\
\hline \multicolumn{4}{|c|}{ Breathing frequency (breaths per min) } \\
\hline At EEV & $41(13)$ & $40(9)$ & $6.7-19.1$ \\
\hline At EIV & $41(9)$ & $42(6)$ & $3.8-8.6$ \\
\hline
\end{tabular}

Results expressed as mean (SD).

${ }^{\star} \mathrm{p}<0.01$, supine $v$ prone; $\mathrm{tp}<0.01$, EEV $v$ EIV; $\mathrm{n}=16$. CL, confidence limit; $t_{d}$, diaphragm thickness; $\Delta t_{d j}$, change in diaphragm thickness during inspiration; $\mathrm{EEV}$, end expiratory volume; EIV, end inspiratory volume.

tions. A $\mathrm{p}$ value of less than 0.05 was considered significant. All studies were approved by the Institutional Review Board of the Memorial Hospital of Rhode Island.

\section{Results}

Table 2 presents the group mean values of $t_{d i}$, $\Delta \mathrm{t}_{\mathrm{di}}$ during inspiration, $\mathrm{SaO}_{2}, \mathrm{HR}$, and $\mathrm{f}$ for the supine and prone positions at EEV and at EIV. No differences in $\mathrm{SaO}_{2}, \mathrm{HR}$, and $\mathrm{f}$ were noted at either position or lung volume. The zone of apposition of the diaphragm to the rib cage was easily visualised and $t_{\mathrm{di}}$ measured in all infants (fig 1). Figure 2 shows individual values of $t_{\mathrm{di}}$. In both positions, $t_{\mathrm{di}}$ is significantly greater at EIV than at EEV. This is not surprising as a normally functioning diaphragm thickens as it shortens during inspiration. However, the values of $t_{\mathrm{di}}$ were significantly greater in the prone position, both at EEV and at EIV $(p<0.01)$. When compared to the supine position, the diaphragm was $14 \%$ thicker at EEV and 23\% thicker at EIV when the infants were prone. In addition, the change in $t_{d i}$ between EEV and EIV was greater in the prone position (30 (7)\% v 20 (3)\% for the prone and supine positions, respectively, $\mathrm{p}<0.05)$. There were no differences in $t_{d i}$ or $\Delta t_{d i}$ between male and female infants in both sleep positions at either lung volume studied.

From measurements of $t_{d i}$ in both positions, we calculated the difference in diaphragm muscle length at EEV between the prone and supine positions (see Appendix). The ratio of diaphragm lengths in the prone and supine positions at $\mathrm{EEV}\left(1_{\mathrm{di}}\right.$ prone: $1_{\mathrm{di}}$ supine) is equal to the ratio of diaphragm thickness in the supine and prone positions ( $t_{\mathrm{di}}$ supine: $\mathrm{t}_{\mathrm{di}}$ prone). Thus, the $14 \%$ increase in $t_{\mathrm{di}}$ at EEV when the infant is prone represents a $13 \%$ shortening of the diaphragm. From measurements of $\Delta t_{\text {di }}$, we also calculated the relative difference in the change in diaphragm length during inspiration - that is, diaphragm shortening $\left(\Delta \mathrm{l}_{\mathrm{di}}\right.$ prone: $\Delta \mathrm{l}_{\mathrm{di}}$ supine) during inspiration, between the prone and supine positions. Diaphragm shortening was, on average, $33 \%$ greater when the infant was prone. 
Skin surface

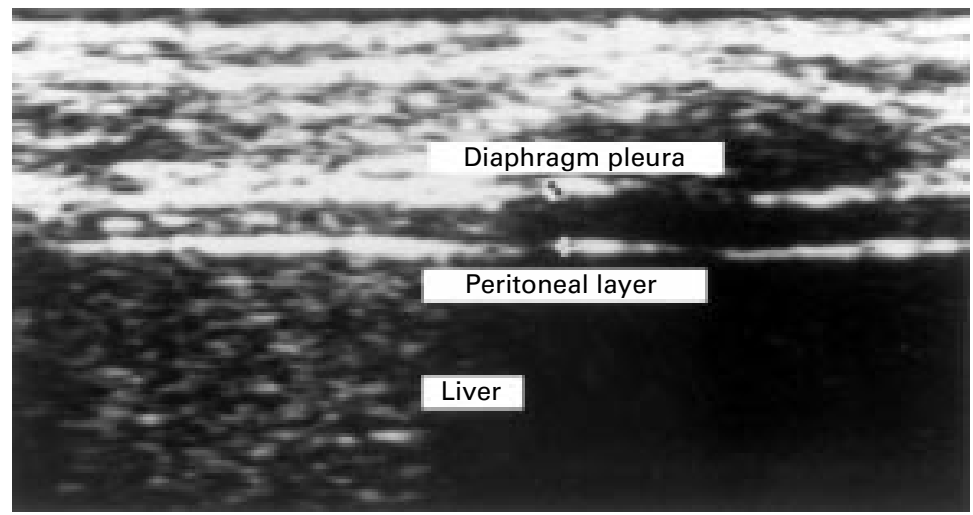

Figure 1 Representative ultrasound image of the zone of apposition depicting the pleural, peritoneal, and muscular layers of the diaphragm at EEV.

\section{Discussion}

Sudden infant death syndrome continues to be the leading cause of infant mortality in developed countries. ${ }^{127}$ Recently, there has been considerable emphasis on infant sleep position as a predisposing factor for SIDS..$^{1-9}$ Retrospective studies examining the link between sleep position and SIDS show that the prone sleep position has a consistent and strong association with SIDS. The likelihood ratios (relative risks or odds ratios) for SIDS with the prone sleep position compared to any other position have ranged from 1.3 to $11.3 .^{2}$ The association between the prone sleep position and SIDS is further supported by the observation that the incidence of SIDS has been significantly reduced in countries that have instituted programmes aimed at reducing sleep time in the prone position ( $42 \%$ reduction in SIDS in the USA). ${ }^{1-4-9} 27$

Despite intense research, the aetiology of SIDS and the explanation of its association with the prone sleep position remain unknown. As the diaphragm is the major muscle of breathing in the neonate, we postulated that position induced alteration in diaphragm function may, in part, explain this association. We

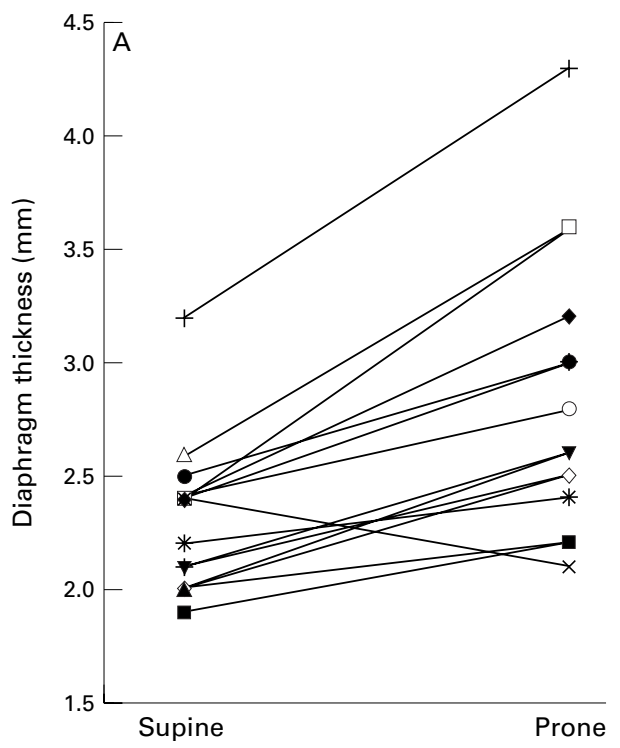

found that, in healthy term infants: (1) the zone of apposition of the diaphragm to the rib cage is readily visualised; (2) the diaphragm is significantly thicker at EEV when the infant is placed in the prone position; and (3) diaphragm thickening is greater during inspiration when the infant is prone. The latter two findings indicate that: (1) the resting length of the diaphragm is shorter in the prone position; and (2) during tidal breathing, the shortening of the diaphragm is greater in that position.

Differences in diaphragm configuration and rib cage anatomy between the newborn and adult have led investigators to postulate that the zone of apposition is minimal or even absent in the neonate. ${ }^{28}$ However, we had no difficulty visualising the zone of apposition in these infants and found that on average it spanned two to three interspaces when measured at EEV. This finding indicates that the diaphragm is coupled to the chest wall, in healthy term infants, in a more advantageous way than previously thought. As the diaphragm descends, it raises gastric pressure in the area of apposition, which, in turn, is inflationary to the lower rib cage. Thus, the disordered chest wall motion noted in neonates may be owing to weakness of the intercostal muscles or to greater rib flexibility, rather than to the lack of a zone of apposition.

The greater $t_{d i}$ noted in the prone position cannot be accounted for by sampling error by the ultrasonographer. Firstly, the large width of the transducer head $(5 \mathrm{~cm})$ relative to the small infant chest wall allowed us to image the diaphragm over several interspaces. Over the range of interspaces sampled, there was uniformity of $t_{\mathrm{di}}$ in a given position. Secondly, we marked the external chest wall such that all measurements of $t_{d i}$ were made at the same external locations of the rib cage in the prone and supine positions. However, despite having the transducer at the same external location, it is possible that a different segment of the

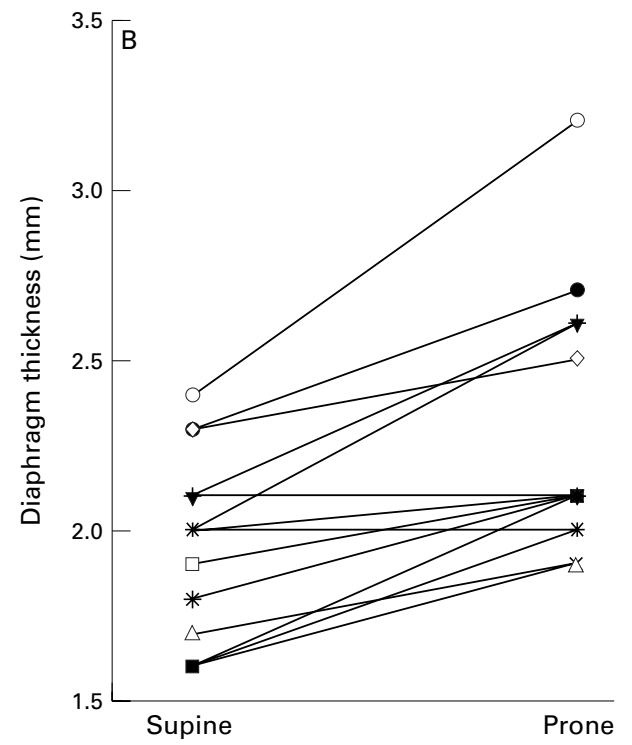

Figure 2 Diaphragm thickness in individual patients in the supine and prone positions at end inspiratory lung volume (A) and at end expiratory lung volume (B). Data from each patient are paired. 
diaphragm was displaced under the transducer head when body position was changed.

Changes in diaphragm length can be inferred from measurements of changes in diaphragm thickness in the zone of apposition. ${ }^{29}$ The volume of the diaphragm muscle is the product of its length, perimeter, and thickness. As the volume of the diaphragm muscle remains constant during diaphragm shortening, length will vary inversely with thickness (see Appendix). The group mean $14 \%$ increase in diaphragm thickness at EEV between the prone and supine positions $\left(t_{\mathrm{di}}\right.$ prone: $t_{\mathrm{di}}$ supine $\left.\times 100\right)$ indicates that the resting length of the diaphragm is $13 \%$ shorter when the infant is prone $\left(1_{\mathrm{di}}\right.$ prone $: 1_{\mathrm{di}}$ supine $\left.\times 100\right)$. A similar degree of diaphragm shortening has been measured in canine diaphragm at EEV when the animal is prone. $^{3031}$ This degree of diaphragm shortening is similar to that seen with an increase in lung volume of $15-30 \%$ of vital capacity. ${ }^{29}$ Such increases in EEV can impair diaphragm performance. In adults, diaphragm strength and endurance as well as the efficiency of breathing are reduced by $40-50 \%$ with this magnitude of increase in lung volume. ${ }^{32}$

The mechanism for the increase in $t_{\mathrm{di}}$ in the prone position is not obvious. Differences in chest wall configuration, in the control of breathing between the two positions, and an increase in EEV could account for the thicker diaphragm when the infants were prone. An increase in EEV would shorten and thicken the diaphragm. However, the effects of the prone position on EEV are controversial. Large increases in EEV have been measured in anaesthetised adults, ${ }^{33}$ whereas no change in EEV was measured in ventilated infants and children. ${ }^{34}$ Alternatively, a change in chest wall configuration, without a change in EEV, may account for this increase in $t_{\mathrm{di}}$ between the two positions. In support of this assertion, Sprung et al found that the diaphragm shortened in dogs placed in the prone position despite no change in $\mathrm{EEV}^{31}$

In addition to being thicker at EEV, the diaphragm thickened more and, therefore, shortened more during inspiration (33\% greater shortening during inspiration) when the infant was prone. This increased shortening may be owing to greater tidal volumes or to more chest wall distortion during inspiration. In support of the former mechanism, previous studies have shown that tidal volume increases and thoracoabdominal synchrony improves when healthy preterm and term infants are placed prone. ${ }^{35} 36$ Our study does not distinguish between these mechanisms. Others, however, have noted no change in tidal volume between the prone and supine positions in healthy preterm infants. ${ }^{19} 37$

The greater diaphragm shortening during inspiration when the infant was prone suggests that the work performed by the diaphragm was greater when the infants were in this position. The work accomplished when a muscle contracts is the integral of its tension over the distance it shortens, or, analogously for the diaphragm, the integral of transdiaphragmatic pressure over the volume displaced. In infants, the high chest wall compliance unopposed by inspiratory rib cage muscle activity often leads to paradoxical inward movement of chest wall during inspiration. Because of this disordered motion, there is less inhaled volume for a given degree of diaphragm shortening. In this instance, the diaphragm is performing more work than calculated from the measurement of tidal volume. ${ }^{38}{ }^{39}$ Our method of measuring $\Delta t_{d i}$ during inspiration circumvents this limitation and provides an alternate means of assessing the work of breathing in infants. Assuming that transdiaphragmatic pressure was similar in both positions, we reasoned that diaphragm work per breath is increased when infants are prone. As the work of breathing increases, the oxygen cost of breathing increases and inspiratory muscle endurance decreases. ${ }^{32}$ We acknowledge that measurements of tidal volume or transdiaphragmatic pressure in these infants would have strengthened this conclusion.

In summary, we have established normal values for diaphragm thickness in healthy term infants and have shown significant differences in diaphragm thickness and the change in diaphragm thickness during inspiration between the supine and prone positions. Contrary to other physiological variables that have been measured, we found that the prone position in term infants is mechanically potentially disadvantageous to the diaphragm. We speculate that reduced mean operating length of the diaphragm in the prone position results in a less efficient and weaker diaphragm. A disadvantaged diaphragm combined with increased work of breathing in the prone position may impair an infant's response to respiratory stresses. In addition to previously proposed factors, our observations suggest the position induced diaphragm dysfunction may be another factor that may underlie the association between the prone sleep position and SIDS. ${ }^{1-3}$ 9-1727 How the diaphragm responds when challenged with respiratory stresses such as upper airway obstruction, hypoxia, or hypercarbia, and how the prone position alters diaphragm function in premature infants remain unknown and need further exploration.

This work was presented at the meeting of the American Thoracic Society, 23-28 April 1999, San Diego, California, USA.

\section{Appendix}

1) Comparison of diaphragm length $\left(1_{d i}\right)$ at $E E V$ between the prone and supine positions.

$\mathrm{m}_{\mathrm{di}}$ supine $=\mathrm{t}_{\mathrm{di}}$ supine $\times \mathrm{p}_{\mathrm{di}}$ supine $\times 1_{\mathrm{di}}$ supine $\quad($ Eq. 1) $\mathrm{m}_{\mathrm{di}}$ prone $=\mathrm{t}_{\mathrm{di}}$ prone $\times \mathrm{p}_{\mathrm{di}}$ prone $\times 1_{\mathrm{di}}$ prone (Eq. 2) where $\mathrm{m}, \mathrm{t}, \mathrm{p}$, and 1 represent diaphragm mass, thickness, perimeter, and length. There was no change in chest perimeter between the supine and prone positions in these 16 infants. Assuming mass is constant.

$1_{\text {di }}$ prone $/ 1_{\mathrm{di}}$ supine $=\mathrm{t}_{\mathrm{di}}$ supine $/ \mathrm{t}_{\mathrm{di}}$ prone

(Eq. 3)

2) Comparison of the change in diaphragm length during inspiration $\left(\Delta \mathrm{l}_{\mathrm{di}}\right)$ between the prone and supine positions. Taking derivatives of Equations 1 and 2, we obtain

$\Delta \mathrm{l}_{\mathrm{di}}$ prone $=\left(-\Delta \mathrm{t}_{\mathrm{di}}\right.$ prone $/ \mathrm{t}_{\mathrm{di}}$ prone $) \mathrm{l}_{\mathrm{di}}$ prone $\quad$ (Eq. 4$)$ and

$\Delta \mathrm{l}_{\mathrm{di}}$ supine $=\left(-\Delta \mathrm{t}_{\mathrm{di}}\right.$ supine $/ \mathrm{t}_{\mathrm{di}}$ supine $) \mathrm{l}_{\mathrm{di}}$ supine $\quad$ (Eq. 5)

The ratio of $\Delta 1_{\mathrm{di}}$ prone $/ \Delta \mathrm{l}_{\mathrm{di}}$ supine is then

$\Delta \mathrm{l}_{\mathrm{di}}$ prone $/ \Delta \mathrm{l}_{\mathrm{di}}$ supine $=\left[\left(-\Delta \mathrm{t}_{\mathrm{di}}\right.\right.$ prone $/ \mathrm{t}_{\mathrm{di}}$ prone $) \mathrm{l}_{\mathrm{di}}$ prone $]$

$/\left[\left(-\Delta \mathrm{t}_{\mathrm{di}}\right.\right.$ supine $/ \mathrm{t}_{\mathrm{di}}$ supine $) l_{\mathrm{di}}$ supine $]$

(Eq. 6) 
Since $1_{\mathrm{di}}$ prone $/ 1_{\mathrm{di}}$ supine $=\mathrm{t}_{\mathrm{di}}$ supine $/ \mathrm{t}_{\mathrm{dp}}$ prone (Eq. 3), substituting for $1_{\mathrm{di}}$ prone $/ 1_{\mathrm{di}}$ supine, we obtain $\Delta \mathrm{l}_{\mathrm{di}}$ prone/ $\Delta \mathrm{l}_{\mathrm{di}}$ supine $=\Delta \mathrm{t}_{\mathrm{di}}$ prone $/ \mathrm{t}_{\mathrm{di}}$ supine $\left(\mathrm{t}_{\mathrm{di}}\right.$ supine $/ \mathrm{t}_{\mathrm{di}}$ prone $){ }^{2}$

1 Task Force on Positioning and SIDS, 1996-1997 (Kattwinkel J, Brooks J, Keenan M, et al). Positioning and sudden infant death syndrome (SIDS): update. Pediatrics 1996;98:1216-18.

2 AAP Task Force on Infant Positioning and SIDS, 1992 (Kattwinkel J, Brooks J, Myerberg D). Positioning and SIDS. Pediatrics 1992;89:1120-6.

3 Skadberg BT, Morild I, Markestad T. Abandoning prone sleeping: effects on the risk of sudden infant death syndrome. F Pediatr 1998;132:340-3.

4 Willinger M, Hoffman HJ, Hartford RB. Infant sleep position and risk for sudden infant death syndrome: report of meeting held January 13 and 14,1994, National Institute of Health, Bethesda, Maryland. Pediatrics 1994; 93:814-19.

5 Dwyer T, Ponsonby A-L, Blizzard L, Newman MN, Cochrane JA. The contribution of changes in the prevalence of prone sleeping position to the decline of sudden infant death syndrome in Tasmania. $\mathcal{F} A M A$ 1995;273 $783-9$

6 Guntheroth WG, Spiers PS. Sleeping prone and the risk of sudden infant death syndrome. $\mathscr{F} A M A$ 1992;267:2359-62.

7 Engelberts AC, deJonge GA. Choice of sleeping position for infants: possible association with cot death. Arch Dis Child 1990;65:462-7

8 Prone, hot, dead. Editorial. Lancet 1990;336:1104.

9 Fleming PJ. Understanding and preventing sudden infant death syndrome. Curr Opin Pediatr 1994;6:158-62.

10 Tonkin SL, Stewart JH, Withey S. Obstruction of the upper airway as a mechanism of sudden infant death: evidence for a restricted nasal airway contributing to pharyngeal a restricted nasal airway contribut

11 Harding R. Nasal obstruction in infancy. Aust Pediatr $\mathcal{f}$ 1986;22(suppl):59-61.

12 Saternus KS, Koebke J, von Tamaska L. Neck extension as a cause of SIDS. Forensic Sci Int 1986;31:167-74.

13 Nelson EA, Taylor BJ, Weatherall IL. Sleeping position and infant bedding may predispose to hyperthermia and the sudden infant death syndrome. Lancet 1989;1:199-201.

$14 \mathrm{Kemp}$ JS, Thach BT. Sudden death in infants sleeping on polystyrene-filled cushions. $N$ Engl f Med 1991;423:185864. 15 Kemp JS, Thach BT. A sleep position-dependent mech-
anism for infant death on sheepskins. Am f Dis Child 1993; 147:642-6.

16 Chiodini BA, Thach BT. Impaired ventilation in infants sleeping facedown: potential significance for sudden infant death syndrome. $\mathcal{F}$ Pediatr 1993;123:686-92.

17 Franco P, Groswasser J, Sottiaux M, et al. Decreased cardiac responses to auditory stimulation during prone sleep. Pediatrics 1996;97:174-8.

18 Martin RJ, Herrell N, Rubin D, Fanaroff A. Effect of supine and prone positions on arterial oxygen tension in the and prone positions on arterial oxygen

19 Wolfson MR, Greenspan JS, Deoras KS, Allen JL, Shaffer TH. Effect of position on mechanical interaction between the rib cage and abdomen in preterm infants. $\mathcal{F}$ Appl Physio 1992;72:1032-8.
20 Heimler R, Langlois J, Hodel DJ, Nelin LD, Sasidharan P. Effect of positioning on breathing pattern of preterm infants. Arch Dis Child 1992;67:312-14.

21 Hutchison AA, Ross KR, Russell G. The effect of posture on ventilation and lung mechanics in preterm and light-fordate infants. Pediatrics 1979;64:429-32.

22 Masterson J, Zucker C, Schulze K. Prone and supine positioning effects on energy expenditure and behavior of low birth weight neonates. Pediatrics 1987;80:689-92.

23 Wagaman MJ, Shutack JG, Moomjian AS, Schwartz JG, Shaffer TH, Fox WW. Improved oxygenation and lung compliance with prone positioning of neonates. $\mathcal{F}$ Pediatr 1979;94:787-91.

24 Bryan AC. Comments of a devil's advocate. Am Rev Resp Dis 1974;110:143.

25 Murphy T, Woodrum D. Functional development of respiratory muscles. In: Polin RA, Fox WW, eds. Fetal and neonatal physiology, vol. 1. Philadelphia: WB Saunders Company, 1998:1071-84.

26 Prechtl HFR. The behavioral states of the new born infant. Brain Res 1974;76:185-212.

$27 \mathrm{http} / /$ www.cdc.gov/nchswww/releases/98news/98news/ sids.htm

28 Devlieger H. Thesis. The chest wall in preterm infants. Katholieke Universiteit Leuven, Leuven, Belgium, 1987: 139.

29 Cohn DB, Benditt JO, Eveloff SE, McCool FD. Diaphragm thickening during inspiration. If Appl Physiol 1997;83: 291-6.

30 Margulies SS, Farkas GA, Rodarte JR. Effects of body position and lung volume on in situ operating length of canine diaphragm. f Appl Physiol 1990;69:1702-8.

31 Sprung J, Deschamps C, Margulies S, Hubmayr RD, Rodarte JR. Effect of body position on regional diaphragm function in dogs. $\mathcal{F}$ Appl Physiol 1990;69:2296-302.

32 McCool FD, Tzelepis GE, Leith DE, Hoppin FG Jr. Oxygen cost of breathing during fatiguing inspiratory resistive loads. F Appl Physiol 1989;66:2045-55.

33 Pelosi P, Croci M, Calappi E, Cerisara M, Mulazzi D, Vicardi P, Gattononi L. The prone positioning during general anesthesia minimally affects respiratory mechanics while improving functional residual capacity and increasing oxygen tension. Anesth Analg 1995;80:955-60.

34 Numa AH, Hammer J, Newth CJ. Effect of prone and supine positions on functional residual capacity, oxygenation, and respiratory mechanics in ventilated infants and children. Am ₹ Respir Crit Care Med 1997;166:1185-9.

35 Adams JA, Zabaleta IA, Sackner MA. Comparison of supine and prone non-invasive measurement of breathing pattern in full term newborns. Pediatr Pulmonol 1994;18:8-12.

36 Hutchison AA, Ross KR, Russell G. The effect of posture on ventilation and lung mechanics in preterm and light-fordate infants. Pediatrics 1979;64:429-32.

37 Warren RH, Alderson SH. Breathing patterns in infants utilizing respiratory inductive plethysmography. Chest 1986; 89:717-22.

38 Heldt GP, Mcilroy MB. Distortion of chest wall and work of diaphragm in preterm infants. F Appl Physiol 1987;62: $164-9$.

39 Guslits BG, Gaston SE, Bryan MH, England SJ, Bryan AC. Diaphragmatic work of breathing in premature human infants. $\mathcal{F}$ Appl Physiol 1987;62:1410-15. 